\title{
A Methodology for Even Power Sharing among Input Sources in a Multiple-Input DC-DC Converter Topology
}

\author{
Shailesh Kumar Nag', Anjanee Kumar ${ }^{2}$ \\ ${ }^{1}$ Raipur Institute of Technology, Department of Electronics and Telecommunication, Raipur, Chhattisgarh, India
}

\begin{abstract}
Among the power electronic converters, dc-dc converters find applications in key areas such as dc drives, battery charging, electric traction, renewable power generation and so on. While many topologies of dc-dc converters are popular, multiple input converters (MICs) have been emerging as practical and efficient means especially for hybrid energy systems. In this paper, a methodology is presented to extract equal powers from multiple (either symmetric or asymmetric) input dc sources of an MIC. The algorithm works on the principle of varying the duty ratios of switches to regulate the average current drawn from each source. Mathematical formulations are presented to describe the scheme. In addition, software based simulation results are presented to validate the proposed methodology.
\end{abstract}

Keywords: Hybrid Energy System (HES), DC/DC converters, Multiple input converters (MICs), Bidirectional power, Power electronic converters.

\section{Introduction}

Power electronics has become an enabling technology for many applications [1]. In principle, it deals with control and conversion of electric power and accordingly these converters are classified as dc-dc, dc-ac, ac-ac and ac-dc converters. Among these, a dc-dc converter has found many applications especially in dc drives, battery charging applications, electric traction, renewable power generation etc. [2]. An emerging application of dc-dc converters is in hybridization of energy. A Hybrid Energy System (HES) comprises of multiple dc sources contributing towards a single/multiple dc load(s). A HES is an emerging technology that can help in meeting future energy requirements. As compared to single source energy systems, HES offers several advantages such as: reliable operation, durability, cleanliness and efficient operation [3, 4]. In terms of practicality, a HES has to address the challenge of integrating multiple sources having different V-I characteristics [5]. In this regard, a class of Multiple-input DC/DC converters (MICs) has emerged and MICs are playing a significant role in interfacing and diversification of different energy sources [6].

In the past few years, several isolated and non-isolated topologies on MIC have been proposed [6-10]. Most of these topologies are inspired from basic $\mathrm{dc}-\mathrm{dc}$ converters. A topology for MIC has been recently proposed in [11] by Sahu and Jain, claimed by the authors to be proficient for the energy diversification from renewable and storage energy sources individually or simultaneously. In [11], the authors have demonstrated the topology being operated in buck, boost and buck-boost modes of operation with the capability of bidirectional power flow to achieve the desired voltage level on either side. In addition, a power management control scheme for the proposed converter is also presented in [11]. In [11], however, no study is made so as to equalize the power drawn from the input dc sources. It is important to administer a control algorithm which leads to even power sharing among the input sources which otherwise would result in unequal lifetimes of the sources and hence increased maintenance [12]. Unequal load sharing may also lead to destabilisation of input de levels [13, 14], thereby causing large ripples and fluctuations. Therefore, in this work, a methodology is proposed to implement power balancing among the multiple input sources which maintaining the desired output voltage.

Rest of the paper is organised as follows. The topology is described in section 2. With the help of mathematical formulations, the proposed methodology is described in section 3. In order to validate the proposed methodology, simulation studies and their results are presented in section 4. Concluding remarks are presented in section 5.

\section{Description of Topology}

The working principle and operation of MIC proposed in [11] is based on the basic dc-dc converter. The passive elements of the converter are charged during a particular period of time and then the stored energy of the passive element is discharged through load during the remaining period of time over a single switching cycle. In MICs, the inductor can be charged by multiple voltage sources instead of single source by adopting an appropriate switching pattern that connects or disconnects multiple sources to the inductor 


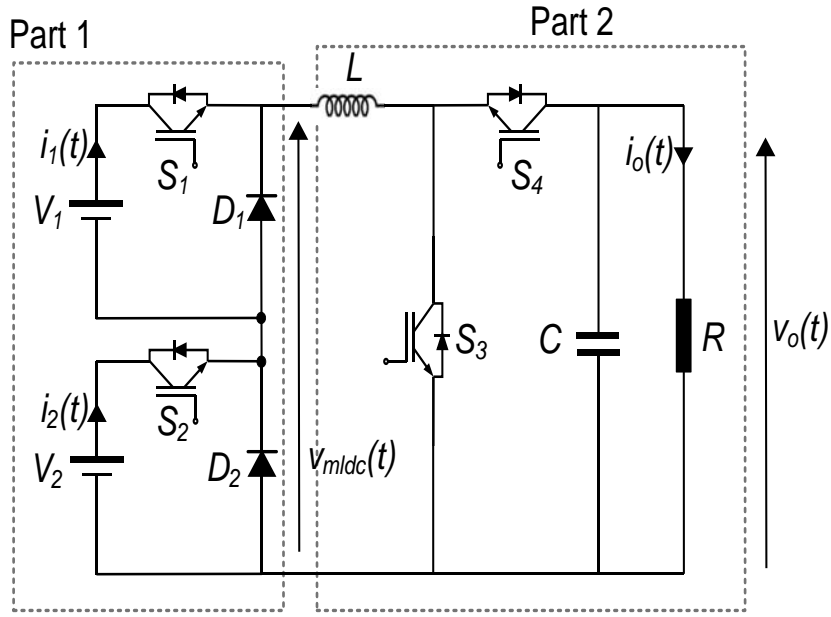

Figure 1: Circuit diagram of proposed MIC topology

individually or simultaneously. The topology as proposed in [11] is shown in Figure 1 with two input sources. It is categorised into two parts: part 1 and part 2. Part 1 is a multilevel dc-link part and it consists of voltage sources $V_{l}$ and $V_{2}$, switches $S_{1}$ and $S_{2}$, diodes $D_{1}$ and $D_{2}$. This part synthesizes a multilevel dc voltage. Part 2 consists of controlled switches $S_{3}$ and $S_{4}$ and energy storage elements $L$ and $C$. Operation of this part decides one of the working modes (buck, boost and bidirectional). Complete operation of the structure is described in [11] with different strategies such as : (a) intermediate synchronisation; (b) rising edge synchronisation; and (c) falling edge synchronisation of switching signals. In Figure 1, the source currents of $V_{l}$ and $V_{2}$ are shown respectively as $i_{1}(t)$ and $i_{2}(t)$ while the dc-link voltage is shown as $v_{\text {mldc }}(t)$ and instantaneous load voltage and current are respectively shown as $v_{o}(t)$ and $i_{o}(t)$.

\section{Proposed Methodology}

The methodology for even power distribution proposed herewith is with reference to Figure 1 with two input sources but it can be extended to any number of input sources with any given asymmetric voltage ratios. It can be observed from Figure 1 that the switch $S_{l}$ and diode $D_{l}$ are complementary in nature, that is to say, when the switch $S_{l}$ is ON, the diode $D_{l}$ is OFF and vice-versa. Thus, if the ON or OFF position of switch $S_{1}$ is known, then the position of the diode $D_{l}$ is automatically known. Similar is the relationship between the switching positions of switch $S_{2}$ and diode $D_{2}$. Thus, let a switching function $\mu(t)$ be defined for a given switch $S$ such that,

$$
\mu(t)=\left\{\begin{array}{l}
0, \text { if power switch } S \text { is } O F F \\
1, \text { if power switch } S \text { is } O N
\end{array}\right.
$$

Thus, the multilevel dc link voltage can be expressed in terms of switching function and input sources as:

$$
v_{m l d c}(t)=V_{1} \mu_{1}(t)+V_{2} \mu_{2}(t)
$$

he average multilevel dc link voltage over a switching period ' $T$ ' can be accordingly expressed as:

$$
V_{\text {mldc }}=\frac{1}{T} \int_{0}^{T}\left\{V_{1} \mu_{1}(t)+V_{2} \mu_{2}(t)\right\} d t
$$

Similarly, the source currents $i_{1}(t)$ and $i_{2}(t)$ can be expressed in terms of switching function and inductor current ' $i_{L}(t)$ ' as :

$$
\begin{aligned}
& i_{1}(t)=i_{L}(t) \mu_{1}(t) \\
& i_{2}(t)=i_{L}(t) \mu_{2}(t)
\end{aligned}
$$

Thus, for any two given sources (and, for that matter

$$
V_{1} * \frac{1}{T} \int_{0}^{T}\left\{i_{L}(t) \mu_{1}(t)\right\} d t=V_{2} * \frac{1}{T} \int_{0}^{T}\left\{i_{L}(t) \mu_{2}(t)\right\} d t
$$

Equation (6) indicates that, for any given load current (and hence inductor current), with the help of appropriate control of the switching functions, average power drawn from input dc sources can be equalized within one switching cycle. This means that appropriate duty ratios $d_{1}$ and $d_{2}$ for $S_{1}$ and $S_{2}$ have to be chosen which would satisfy the relationship:

$$
d_{1} V_{1}=d_{2} V_{2}
$$

Under this condition, however, as per equation (2), the average multilevel dc link voltage will be regulated depending on the ratio of $d_{1}$ to $d_{2}$. Accordingly, to obtain a desired voltage at the load, $V_{m l d c}$ has to be treated as the input to 'part 2' of the converter topology.

\section{Simulation Results}

With reference to figure 1 , let the magnitudes of voltage sources be binary with values $V_{1}=24 \mathrm{~V}$ and $V_{2}=12 \mathrm{~V}$. Accordingly, as per equation (7), $d_{2}$ should be taken twice of $d_{1}$. Hence $\mathrm{d}_{1}$ is taken to be 0.1 while $\mathrm{d}_{2}$ is taken as 0.2 , with a switching frequency of $10 \mathrm{kHz}$. Thus, as per equation (3), the average value of multilevel dc link would be $V_{1} d_{1}+V_{2} d_{2}$ i.e. $4.8 \mathrm{~V}$. Now, let us say that the average output voltage desired at load is $18 \mathrm{~V}$, then it means that the multilevel dc link voltage is needed to be boosted and hence the switch $S_{3}$ has to be operated with a duty ratio $d_{3}$, obtained by using the standard expression for boost conversion,

$$
V_{o}=\frac{V_{m l d c}}{\left(1-d_{3}\right)}
$$

Hence, under the conditions described, $d_{3}$ should be chosen to be 0.73 .

In order to verify the concepts proposed herewith, a simulation study is performed using MATLAB/Simulink software along with SimPowerSystem toolbox. The parameters are summarized in Table 1. 


\section{International Journal of Science and Research (IJSR) \\ ISSN (Online): 2319-7064}

Index Copernicus Value (2013): 6.14 | Impact Factor (2014): 5.611

Table 1: Parameters of MIC for simulation study

\begin{tabular}{|c|c|c|}
\hline Parameter & Unit & Value \\
\hline Source $V_{l}$ & {$[\mathrm{~V}]$} & 24 \\
\hline Source $V_{2}$ & {$[\mathrm{~V}]$} & 12 \\
\hline Inductance $L$ & {$[\mathrm{mH}]$} & 14.4 \\
\hline Capacitance $C$ & {$[\mu \mathrm{F}]$} & 216 \\
\hline Frequency $f$ & {$[\mathrm{kHz}]$} & 10 \\
\hline Resistance $R$ & {$[\Omega]$} & 10 \\
\hline Duty ratio $d_{1}$ & {$[\%]$} & 10 \\
\hline Duty ratio $d_{2}$ & {$[\%]$} & 20 \\
\hline Duty ratio $d_{3}$ & {$[\%]$} & 73 \\
\hline Output voltage $V_{o}$ & {$[\mathrm{~V}]$} & 18 \\
\hline
\end{tabular}

Table 2: Power readings

\begin{tabular}{|c|c|c|}
\hline Load & Source $V_{l}$ & Source $V_{2}$ \\
\hline $30 \mathrm{~W}$ & $17 \mathrm{~W}$ & $17 \mathrm{~W}$ \\
\hline
\end{tabular}

The instantaneous output voltage obtained from the simulation model is shown in figure 2. The ripples are seen to be within the range of $5-10 \%$ while the average output voltage is $17.25 \mathrm{~V}$. The inductor voltage and currents are shown respectively in figures 3 and 4 . In addition, the source currents from sources $V_{l}$ and $V_{2}$ are shown in figures 5 and 6. The load power and powers drawn from sources $V_{1}$ and $V_{2}$ are shown in Table 2 and it can be seen that both the sources impart equal power to the load, while the primary goal of voltage regulation is simultaneously achieved. Hence, it can be safely said that the proposed scheme works satisfactorily.

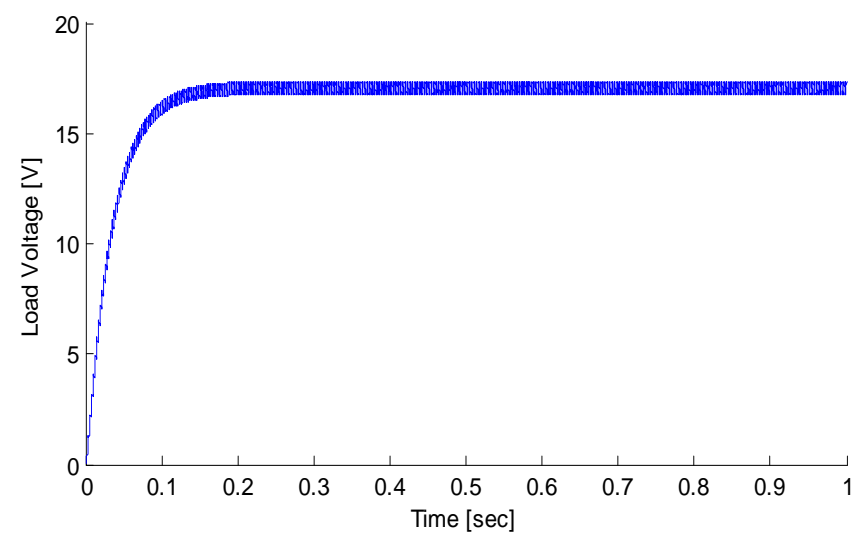

Figure 2: Simulated waveform for the load voltage

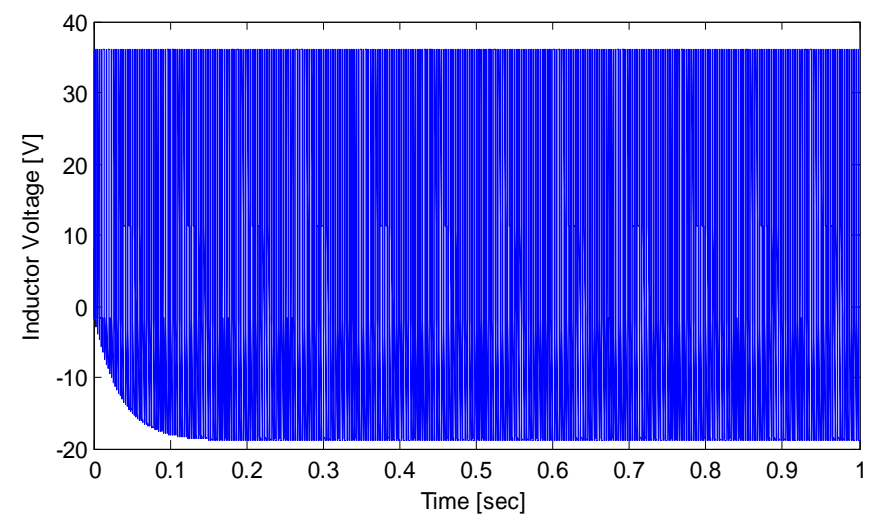

Figure 3: Simulated waveform for the inductor voltage

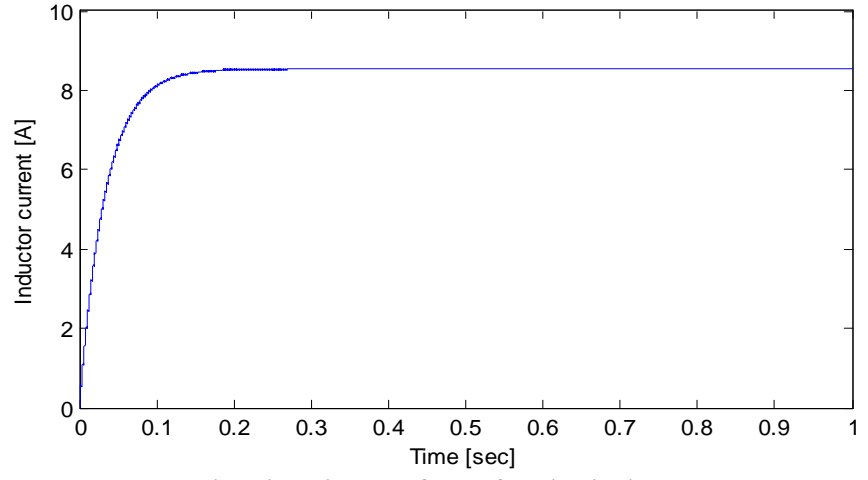

Figure 4: Simulated waveform for the inductor current

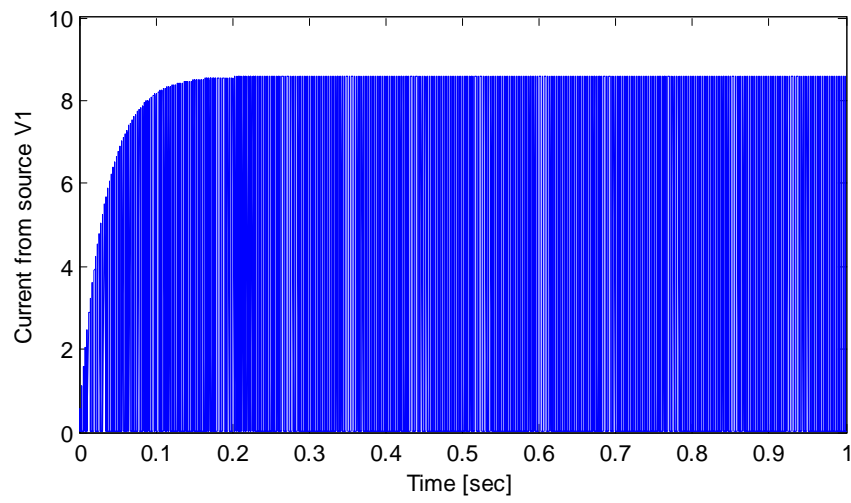

Figure 5: Simulated waveform for the current drawn from source $V_{l}$

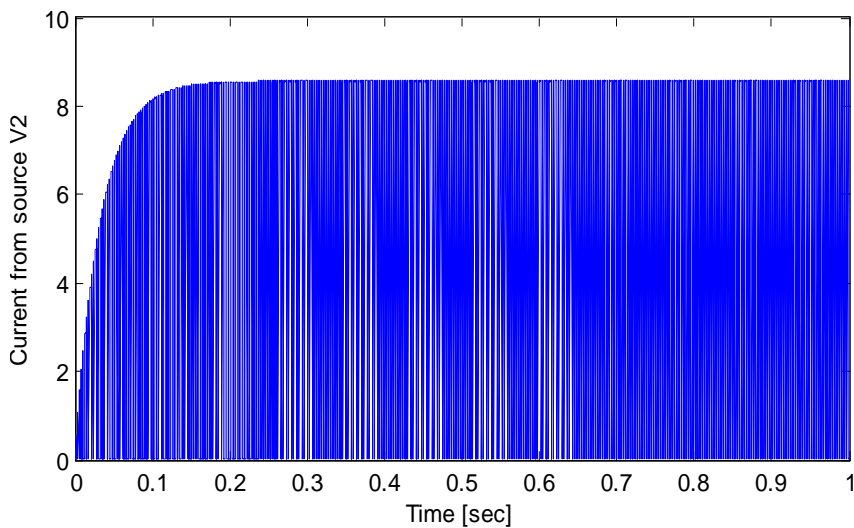

Figure 6: Simulated waveform for the current drawn from source $V_{2}$

\section{Conclusion}

In this paper, a methodology to extract equal average powers from multiple input dc sources in a dc-dc converter topology is presented. The sources voltages may be equal or unequal and accordingly the currents are drawn from the given sources such that the average powers drawn are equated and hence their lifetimes are enhanced. Because of the presence of multiple switching states, both the objectives are obtained: regulation of average output voltage and even power sharing among the input dc sources. Proposed concepts are validated with the help of modeling and simulations carried out with MATLAB/Simulink software package. Obtained results are satisfactory. 


\section{International Journal of Science and Research (IJSR)}

ISSN (Online): 2319-7064

Index Copernicus Value (2013): 6.14 | Impact Factor (2014): 5.611

\section{References}

[1] P. Gueguen, "How power electronics will reshape to meet the 21st century challenges?," In Power Semiconductor Devices \& IC's (ISPSD), 2015 IEEE 27th International Symposium on, vol., no., pp.17-20, 10-14 May 2015.

[2] F. Blaabjerg; A. Consoli ; J.A. Ferreira ; J.D. van Wyk, "The future of electronic power Processing and conversion," In Power Electronics, IEEE Transactions on, vol.20, no.3, pp.715-720, May 2005.

[3] J. Cao; A. Emadi, "A New Battery/Ultra Capacitor Hybrid Energy Storage System for Electric, Hybrid, and Plug-In Hybrid Electric Vehicles," In Power Electronics, IEEE Transactions on, vol.27, no.1, pp.122-132, Jan. 2012.

[4] F. Valenciaga; P.F. Puleston, "Supervisor control for a stand-alone hybrid generation system using wind and photovoltaic energy," In Energy Conversion, IEEE Transactions on, vol.20, no.2, pp.398-405, June 2005.

[5] S. Kumar; H.P. Ikkurti, "Design and control of novel power electronics interface for battery-ultracapacitor Hybrid Energy Storage System," In Sustainable Energy and Intelligent Systems (SEISCON 2011), International Conference on, vol., no., pp.236-241, 20-22 July 2011.

[6] S.H. Choung; A. Kwasinski, "Multiple-input DC-DC converter topologies comparison," In Industrial Electronics, 2008. IECON 2008. 34th Annual Conference of IEEE, vol., no., pp.2359-2364, 10-13 Nov. 2008.

[7] Wu Hongfei; Xu Peng; Hu Haibing; Zihu Zhou; Yan Xing, "Multiport Converters Based on Integration of Full-Bridge and Bidirectional DC-DC Topologies for Renewable Generation Systems," In Industrial Electronics, IEEE Transactions on, vol.61, no.2, pp.856-869, Feb. 2014.

[8] H. Tao; A. Kotsopoulos; J.L. Duarte; M.A.M. Hendrix, "Family of multiport bidirectional DC-DC converters," In Electric Power Applications, IEEE Proceedings -, vol.153, no.3, pp.451-458, 1 May 2006.

[9] J.T. Hawke; H.S. Krishnamoorthy; P.N. Enjeti, "A multiport power sharing converter topology for renewable-to-grid interface," In Energy Conversion Congress and Exposition (ECCE), 2014 IEEE, vol., no., pp.4992-4999, 14-18 Sept. 2014.

[10] O. Hegazy; M. El Baghdadi; J. Van Mierlo; P. Lataire; T. Coosemans, "Analysis and modeling of a bidirectional multiport DC/DC power converter for battery electric vehicle applications," In Power Electronics and Applications (EPE'14-ECCE Europe), 2014 16th European Conference on , vol., no., pp.1-12, 26-28 Aug. 2014.

[11] L. Kumar; S. Jain, "Multiple-input DC/DC converter topology for hybrid energy system," In Power Electronics, IET, vol.6, no.8, pp.1483-1501, September 2013.

[12] K.K. Gupta; S. Jain, "A Novel Multilevel Inverter Based on Switched DC Sources," In Industrial Electronics, IEEE Transactions on, vol.61, no.7, pp.3269-3278, July 2014.

[13] K.K. Gupta; S. Jain, "Topology for multilevel inverters to attain maximum number of levels from given DC sources," In Power Electronics, IET, vol.5, no.4, pp.435-446, April 2012.

[14] M. Angulo; P. Lezana; S. Kouro; J. Rodriguez; B. $\mathrm{Wu}$, "Level-shifted PWM for cascaded multilevel inverters with even power distribution," In Proceedings of the IEEE Power Electronic. Spec. Conf., pp.2373 2378 .

\section{Author Profile}

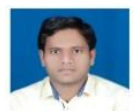

Shailesh Kumar Nag received B.E. degree in Electronics and Telecommunication Engineering from Chhattisgarh Institute of Technology, Rajnandgaon, Chhattisgarh, India in 2011 and is currently a M.E. scholar from Raipur Institute of Technology. His current area of research is Hybrid Energy System.

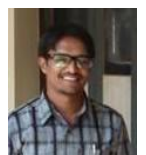

Anjanee Kumar is an assistant professor in the Department of Electronics and Telecommunication Engineering, Raipur Institute of Technology. His current area of interest is Power Electronics. 